\title{
MODALS AS A PROBLEM FOR MT
}

\author{
by Bengt Sigurd \& Barbara Gawrónska \\ Dept of Linguistics and Phonetics, Lund University, Sweden \\ e-mail:Bengt.Sigurd@ ling.lu.se
}

\begin{abstract}
Summary
The paper demonstrates the problem of translating modal verbs and phrases and shows how some of these problems can be overcome by choosing semantic representations which look like representations of passive verbs. These semantic representations suit alternative ways of expressing modality by e.g. passive constructions, adverbs and impersonal constructions in the target language. Various restructuring rules for English, Swedish and Russian are presented.
\end{abstract}

\section{Introduction}

Modal verbs belong to the most lrequent English words. Clauses with modal expressions make up a considerable part of the clauses of any text, why any MT-system which is claimed to cover empirical texts with reasonable quality must include solutions to the problems discussed in this paper (cl. An et al, 1993 for a corpus based approach). One of the problems connected with the analysis of such clauses is the lact that the distinction between auxiliaries and modals is not clear. Verbs like ought to and dare (to) are often labelled semiauxiliaries, begin and continue are called aspectual verbs etc. A common denominator of auxiliaries, semi-auxiliaries, modals and several perception verbs is their "anxiliary meaning" including tense, modality and aspectual perspective (ce. Gawrońska, 1993). In the following, the term "auxiliary "will be used even when referring to verbs traditionally called modals and pereption verts.

The typical "auxiliary" meanings, e.g. modality, aspectual perspective and tense show great encoding variation between languages. And even within one language one may olien choose between several different lexicalgrammatical modes. In English one maly choose between $X$ may come, It is possible that $X$ comes, and $X$ possibly comes with only minor stylistic differences.

Swedish kan has both a root meaning (equivalent to is able to) and an epistemic meaning (equivalent to may), while English can only has the lirst meaning. The mode of encoding auxiliary meanings may be even more differentiated in other languiges. Thus, He must come, has to be rendered by the passive construction $I l$ est obligé de venir or the impersonal construction Il faut qu'il vienne in French. In Russian one would have had to render this sentence using an an adjective (dolžen) or an adverb (nado, neobxodimo). Japanese would have to use konakereba narimasen (literally: "It won't do if X does not come"). MT-systems dealing with a certain pair of languages may tailor the meaning representations of auxiliaries ad hoc, but multilanguage systems such as Swetra, the Swedish Computer Translation Project (Sigurd \& Gawronska, 1990), must choose more universal representations and suitable restructuring transfer rules as will be demonstrated. The problem of modality is also of general interest for linguistic, semantic and cognitive theory (Sweetser, 1990).

\section{English Verb Phrases}

There are two basic types of verb phrases in English (ct Sigurd, 1992), one (1) consisting only of a linite main verb (with possible complements), e.g. Bill jumps, the other (2) consisting of a linite auxiliary verh followed by a non-finite main verb (with possible complements), e.g. Bill must jump. The nonlinite main verb in the second type may be in the infinitive without to as illustrated, or in an infinitive with to as in Bill began to jump. The non-linite verb maly also be a past participle as in Bill has jumped or a present participle as in Bill began jumping. The choice between nonlinite loms is an atutomatic consequence of the preceding verh. We note that the have meaning perfect tense takes the perlect participle as in Bill has jumped, while the have which is an equivalent of mmst takes the infinitive with to as in Bill has to juml. The verb begin maly take an inlinitive with to (Bill began to jump) or alternatively a present participle (Bill began jumping). The auxiliaries in other languages, e.g. German and Swedish display similat combinatorial properties.

The second type of verb phrase mentioned may be expanded to include further non-linite auxiliatries, as illustrated in: Bill must begin to jump.Bill must dare to begin to jump and Bill. must dare to begin to be able to jump.

Occasionally there maly be a short adverb between the non-linite forms as in Bill must 
dare not to jump and even alter a to as in Bill. must dare to not jump, although the so called split infinitive construction is condemned by prescriptive grammarians.

\section{Semantic Representations of Verb Phrases}

The meaning complexes corresponding to the verb phrases described may simply be rendered as lists of the constituent verb meanings, where the tense of the linite verb is shown, but the particular form of non-linite verbs and the occurrence or non-occurrence of infinitive markers are not shown. This is the approach taken by Swetra. The lexical meaning representations or semantic markers in Swetra are of the form $m(S, G)$, where $m$ denotes meaning, $S$ is the main meaning of the word denoted by a kind of Machinese Linglish and $G$ the grammatical meaning. "The verb form jumps has the representation $m$ (jump, pres). The meanings of the infinitive form (to) jomp, the past participle jumped and the present participle jumping are all rendered as $m(j a m p)$, nonf). The following lable shows some preliminary meaning representations of verb phrases under the phrases.

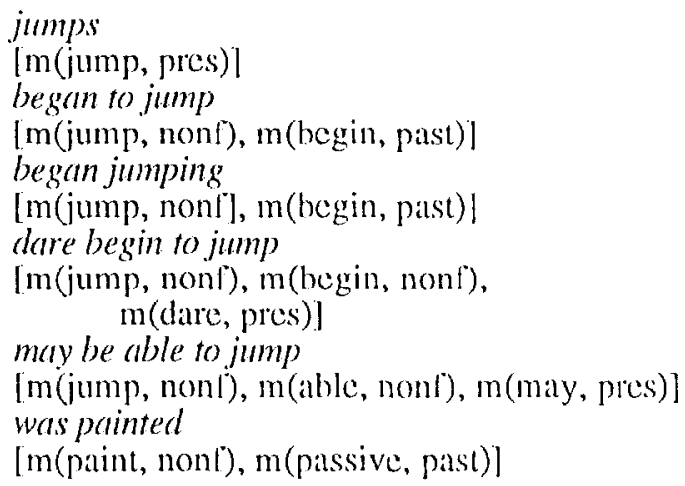

The semantic representations illustrated have the main verb first and the order of the verbs is thus reversed il compared to English. The order chosen is arbilatry. We have illustalled the representation ol a passive phrase was painted as well. This representation is also used for the Swedish morphological passive which is malades (there is also a syntactic passive in Swedish: blev mailad).

\section{Passive Meaning Representations for some Auxiliaries}

Linguists have often talked about the meanings of auxiliaries using words and concepts such as: compulsion, obligation, pormission, ability, necessity, probability and possibility. Words which can be associated with compulsion and obligation, c.g. must, shall, onght to have been called deontic. A distinction between a root meaning and an epistemic meaning has been observed for a number of atuxiliaries, e.g. must, where the two meanings are illustrated by the following two cxamples (liom Sweetser, 1990, p, 49).

Bill mast be home by ten; Mother won't let him stay out any longer

\section{Bill mast be home already; I see his coat}

The epistemic meaning may also be rendered by sentence adverbials as illustrated by: Bill is evidently/seemingly home or an impersonal expression with an adjective as in It is clear/ obvious that Bill is home. It would be an advantage il the semantic representations of auxiliatries could be related in a simple way to the meaning representations of such equivalent adverbs and adjectives.

The simplest way to represent the meanings of auxiliaries is illustrated by $m$ (can, pres). It is then logical to choose $m(\mathrm{com}$, nonf) lor the assumed infinitive be able to. Similatly, one maly represent the meaning of present mast by $m$ (must, pres) and and the meaning of the corresponding infinitive be obliged to by $m$ (must, nonf). The phrase be obliged to can, however, also be regarded as a passive in which case it would be represented as: [m(oblige, nonf), m(passive, nonf)]. With this representation in mind one may represent present must as / m(oblige, nonf), $m$ (passive, pres)/ instead andcan as / m(able, nonf), $m$ (passive, pres)/ which directly gives us the synonym is able to.

There are further semantic arguments in favour of representing constuctions with modal verhs in a waly similar to passive clauses. The relerent of the subject in a sentence with a modal verb is not as "agentive" as the referent of the subject of a typical active content verb. It the term agent is to be understood as the element of the event-situation that is actively involved in and responsible lor the triggering of the cvent-situation in question (Gawronskat 1993), it becomes clear that the subject of a modal comstruction is not a typical agent. Its responsibility for triggering the event-situation is reduced by the obligation, allowance or compulsion component. In Russian and Polish, this property of the subject referent is overtly expressed by the dative case in several modal construction. The equivalent of the English of Swedish subject in Russian sentences with nado ("it is obligatory"), 
neobxodimo ('il is necessary'), nel'zia ('il is not allowed') or Polish wolno ('it is allowed') occurs in the dative, a case normally associated with the semantic roles 'beneficiary' or' 'experiencer'.

\section{Passive representations of some English auxiliaries}

One may hesitate when choosing terms in the meaning representations as is obvious from works on modals. The following are used by Swetra.

${ }^{*}$ allowance $* /$

elex([m(allow, nonf), m(passive, pres)], v, aux, fin, ., 1, inl, i, [1) $\rightarrow$ - [may].

The semantic representation /m(allow, nonf), $m$ (passive, pres)] of the finite form may makes it comparable to the meaning representations of is/was allowed/permitted to and the inlinitive be allowedpermitted to. This meaning may be illustrated by Bill maty come (as he asked). The form may may have another (epistemic) meaning as well (below).

/*obligation */

elex([m(oblige, nonf), $m$ (passive, pres)], $v$, aux, fin,, 1, inf, i, [1) $\rightarrow$ [must].

The representation [m(oblige, nonl), $\mathrm{m}$ (passive, pres)] gives is obliged to as a synonym as is generally suggested in glammars.

$I^{*}$ capability */

elex([m(able, nond), m(passive, pres)], $v$, atux, fin, , 1, ini, i, [1) $\rightarrow$ |can $\mid$.

This representation makes it possible to get is able to as a direct synonym and the infinitive be able to which is clesirable.

${ }^{*}$ epistemic appearance */

elex(|m(perceive, nonf), m(passive, pres) I, v, aux, lin, agr $(p l, \ldots, \ldots), 1$, toinl, $i$, I1) $\rightarrow\{\sec m\}$.

This analysis makes the phrase Bill is perceived to come parallel to Bill seems to come, which is reasonable, although the first phrase seems to be too specilic and implies a latent agent. This epistemic meaning is also expressed by grammarians by such words as: inlerence, conclusion.

There is a number of epistemic expressions which indicate the sense modality of the perception more or less clearly as illustrated by: Bill is saidheardffelt to come.
/* epistemic possibility, probability, certainty

elex $([m$ (possible, nonf), m(passive, pres $)], v$, aux, lin, ., 1, inf, i, [i) $->$ [mayl.

clex([m(probable, nonl"), m(passive, pres)], v, aux, fin, , 1, toinl, $\mathrm{i},[]) \rightarrow$ [ought].

$\operatorname{clex}([\mathrm{m}$ (certain, nonf), m(passive, pres)], $v$, aux, fïn, , 1, inf, i, [1) $->$ [shall].

The semantic representations of auxiliaries must be sensitive to the presence/absence of negation. The equivalent of English must, when not negated, is the etymologically related Swedish verb miste, whereas must not is not to be rendered by maste inte ('must' not), but by fir inte ("is not allowed to'). The need for altention to negation becomes even more conspicuous when considering the eflects of the interplity between negation and aspect in taanslation between Russian and English (el. Isačcnko 1962:198):

a. nado vernut' knigu

'must' return-pert book-ace

'one has to return the book/the book must be returned"

b. nado vozvrašc̆at' knigi

'must' return-imp books-nom/ace

'one oughe to return books'

c. ne nado vozvraščal' étu knigu

neg 'must' return-imp this book-ace

'one does not need/have to return this book'

The problem of translation between English and Russian can be solved by lexically encoded negation and aspect control, according to patterns like the lollowing:

clex([m(oblige, non $\left.l^{\circ}\right), m$ (passive, pres)], $v$, aux, lin,, 1 , inl, $i,[]) \rightarrow$ [must].

rlex(|m(oblige, nonl).m(passive, pres)|, adv, mod, inl, [perl], 1, , , [1]) $\rightarrow$ [nidol.

The Russian lexical entry (rlex) contains the information that an English modal verb with the meaning code m(obligue, nonf), $m$ (passive, pres) is to be rendered by the Russian modal adverb nado, provided that nado is not negated and that it is combined with a perfective infinitive clause [perf]. Negation would have shown in the slot now marked [perl']. This pattern covers cases exemplified by a. The other patterns are handled in an analogous way. 
English and Swedish equivalents

It is evident from the analysis above that there is a number of auxiliaries which ean be translated directly as a consequence of the semantic representations suggested. Table ! shows corresponding English and Swedish

Table 1: English and Swedish equivalents

/* allowance */

[m(allow, nonf), m(passive, pres)]

/* obligation */

[m(oblige, nonf), m(passive, pres)]

$1 *$ capability */

[m(able, nonl), m(passive, pres)]

* epistemic appearance $* /$

[m(perceive, nonl), m(passive, pres)]

I* epistemic possibility etc * $/$

[m(possible, nonf), m(passive, pres)]

[m(probable, nonf), m(passive, pres)]

[m(certain, nonl), m(passive, past)] aluxiliaries, adverbs and adjectives which one would also like to be able to transtate between.

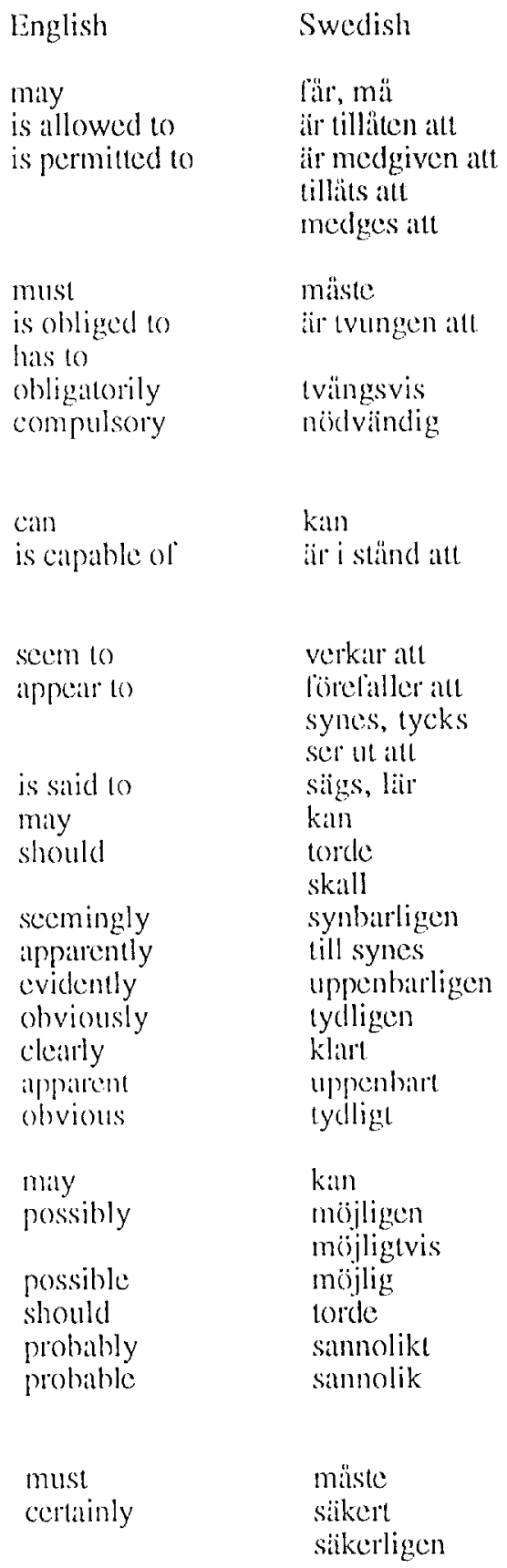




\section{Deriving Parallel Constructions}

If there is no equivalent auxiliary in the target lexicon an advanced MT-system may try to find an equivalent by deriving parallel constructions e.g. with adverbials. It will then have to make changes in the functional representation and move parts of the meaning representations. The following is a general Prolog rule, which moves the epistemic meaning from the predicate to the adverb. The rule assumes the analysis of auxiliaries presented above and suitable lexical representations. The rule states that if there is a structure such as $A$, there is also $B$.

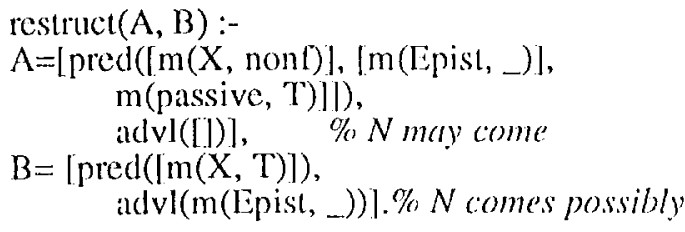

Note how the tense morpheme ( $\mathrm{T}$ ) is also moved.

The following rule illustrated how It is possible that Bill comes can be derived. It presupposes a certain syntactic analysis where English it is represented as impers.

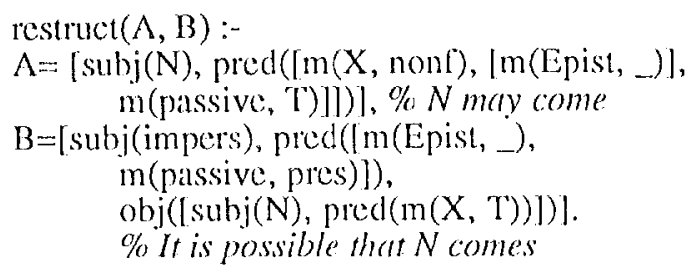

In translation from and into Russian, there is a need for rendering an impersonal construction, like nado vernut' knigu, into an English or Swedish construction with an overtly realized subject (E. The book must be refurned, S. Boken maiste liimmas tillbaka). In such cases, the 'restruct' rules move the representation ol the Russian object into the subject slot of the target representation and instantiate the mode variable in the constant 'passive', "The definiteness value of the subject is assumed to be, by default, +delinite, which generally holds for perfective constructions with singular objects and preverhal subjects.

restruct $(A, B)$ :-

$A=[\operatorname{subj}([]), \operatorname{pred}([m($ Verb, $[$ nonl, perl] $])$, Aux, Tense, Mode $\mid)$, obj(m(Z, _ $))]$. $\%$ nado vernut' knigut
$B=[\operatorname{subj}(m(Z$, del $)), \operatorname{pred}([m($ Verb, nonl $)$, Aux, m(passive, 'Tense)])!! \% the book must be returned

As an altemative, the empty subject slot is filled by a generic personal (genpers) pronoun (E. one, S. man):

restruct $(A, B)$ :-

$A=[\operatorname{subj}([\mid]), \operatorname{pred}([m($ Verb, $\mid \operatorname{non}[, \operatorname{per}[])$, Aux, Tense, Mode]), obj(m(Z,_))], \% nado vernut' knigu

$B=\left[\operatorname{subj}\left(m\left(\right.\right.\right.$ genpers, $\left.\_\right), \operatorname{pred}([\mathrm{m}($ Verb, nonf $)$, Aux, $m$ (passive, Tense)]), obj(m(Z, dem))].

\% one must retum this book

Such rules may be used as transfer rules in MT systems. They may also be used in order to derive synonymous expressions in the same language. Some subtle semantic and stylistic differenees between the target and the source sentences sometimes occur. However, the translations are generally comprehensible.

\section{References}

An, D. U., Kim, G. C., Lee, J. H \& Muraki, K. 1993. Corpus Based Modality Generation for Korean Verbs in Pivot E/JK System. Proc. NLPRS' '93, Fukuoka, Japan, 25-34

Coates, J. 1983. The Semantics of Modal Auxiliaries. Croom Helm

Galwronska, B. 1993. An MT Oriented Model of Aspect and Article Semantics. Lund. Lund University Press

Isacenko, A. V. 1962. Die russische Sprache der Gegenwart. Teil I: Formenlehre. Halle (Siale): VEB Max Nicmayer Verlag.

Sigurd, B 1992 "A New Analysis for Machine Translation of the Auxiliary and Main Verb Complex". Studia Linguistica 46:1, 3()-48

Sigurd, B. \& Gawronska, B. 1988 "The potential of Swetra - a Multilanguage Translation System". Computers and Translation 3, 237-250)

Sweetser, E. 1990 From Etymology to Pragmatics. Cambridge Studies in Linguistics 54 